\title{
Effect of sharing health messages on antenatal care behavior among women involved in microfinance-based self-help groups in Bihar India
}

Monika Walia ${ }^{1}$, Laili Irani ${ }^{1 *}$, Indrajit Chaudhuri ${ }^{2}$, Yamini Atmavilas $^{3}$ and Niranjan Saggurti ${ }^{1}$

\begin{abstract}
Background: Bihar state in India has one of the highest rates of maternal and infant mortality in South Asia. Microfinance-based self-help groups (SHGs), involving rural women, are being utilized to improve maternal and child health practice and reduce mortality. SHG members receive information on key maternal and child health practices as well as encouragement for their practice. This study measures the association of health messaging to SHG members with their antenatal care (ANC) behaviors.
\end{abstract}

Methods: The study was conducted in eight districts of Bihar in 2016. A three-stage cluster sampling design (with a random selection of blocks, villages, and SHGs) selected the sample of 1204 SHG members who had an infant child; of these, 597 women were members of SHGs that received dedicated sessions on health messages, while 607 women belonged to SHGs that did not. To examine the impact of the health intervention on ANC practice, radius caliper method of propensity score matching controlled for various socio-demographic characteristics between the two groups.

Results: Most of the interviewed women (91.5\%) belonged to a scheduled caste or tribe. Nearly $44 \%$ of SHG members exposed to the health intervention were engaged in some occupation, compared to 35\% of those not exposed to the intervention. After matching unexposed SHG women with exposed SHG women, no significant differences were found in their socio-demographic characteristics. Findings suggest that exposure to a health intervention is associated with increased likelihood of at least four ANC visits by SHG women (ATE $=7.2,95 \% \mathrm{Cl}$ : 0.76-13.7, $p<0.05$ ), consumption of iron-folic acid for at least 100 days (ATE $=8.7,95 \%$ Cl: 5.0-12.5, $p<0.001$ ) and complete ANC (ATE $=3.6,95 \%$ Cl: $2.3-4.9, p<0.001$ ), when compared to women not exposed to the health intervention.

Conclusions: The study shows that sharing health messages in microfinance-based SHGs is associated with significant increase in ANC practice. While the results suggest the potential of microfinance-based SHGs for improved maternal health services, the approach's sustainability needs to be further examined.

Keywords: Self-help group (SHG), Antenatal care (ANC), Propensity score matching (PSM), Health integration, Health messaging, ANC outcomes, Bihar India

\footnotetext{
*Correspondence: laili.ir@gmail.com

'Population Council, Zone 5A, Ground Floor India Habitat Centre, Lodi Road,

New Delhi, Delhi 110003, India

Full list of author information is available at the end of the article
}

(c) The Author(s). 2020 Open Access This article is distributed under the terms of the Creative Commons Attribution 4.0 International License (http://creativecommons.org/licenses/by/4.0/), which permits unrestricted use, distribution, and reproduction in any medium, provided you give appropriate credit to the original author(s) and the source, provide a link to the Creative Commons license, and indicate if changes were made. The Creative Commons Public Domain Dedication waiver (http://creativecommons.org/publicdomain/zero/1.0/) applies to the data made available in this article, unless otherwise stated. 


\section{Background}

India was unable to achieve its Millennium Development Goal 5, reduction of maternal mortality, primarily due to high rates of maternal mortality in states such as Bihar. According to the Sample Registration System 20112013, Bihar's maternal mortality ratio (MMR) was estimated at 208 deaths out of 100,000 live births, higher than the national MMR of 167 deaths per 100,000 live births [1]. Reducing Bihar's MMR will enable the nation to come closer to meeting its Sustainable Development Goal 3.1 of reducing its MMR to less than 70 per 100 , 000 live births by 2030 .

The World Health Organization's (WHO) Safe Motherhood Program identifies antenatal care (ANC) as one of four domains for prevention of maternal and infant mortality [2]. Several studies show that ANC provides opportunities for identifying pregnancies at risk and increasing safe deliveries [3, 4].

Recent data from India suggest that while $51.2 \%$ of women nationally make four or more ANC visits, only $14.4 \%$ of women in Bihar do [5]. In addition, only 3.3\% of pregnant women in Bihar receive complete ANC (i.e. at least four ANC visits, at least one tetanus toxoid (TT) injection, and iron-folic acid (IFA) tablets or syrup for 100 days or more) [6]. Studies in similar contexts have identified reasons for lack of complete ANC, such as keeping pregnancy secret (for cultural reasons), lack of perceived ANC benefits, family member discouragement, direct and indirect costs, lack of transportation, inadequate infrastructure, distances to clinics, lack of accompaniment for ANC visits, and poor healthcare staff attitudes $[4,7]$.

Microfinance-based women's collective organizations, called self-help groups (SHGs), provide a promising social medium through which messages to increase ANC coverage can be shared [8-10]. These messages are shared through a behavior change communication (BCC) approach, coupled with self-generated community mobilization among group members. A few studies have measured the effects on maternal and child health from community-based interventions implemented through women's SHGs. The Makwanpur trial in Nepal implemented a participatory learning cycle through women's SHGs that was followed by an $88 \%$ reduction in maternal mortality and a $30 \%$ reduction in neonatal mortality after 3 years [11]. Similar interventions in the Indian states of Jharkhand and Orissa found that infants born to SHG mothers had significantly improved chances of survival within the first 6 weeks of life compared to infants born to women who were not SHG members [12]. These studies, however, fail to measure effects of such interventions at scale, and with comparison groups as controls, impeding the scalability and sustainability of such interventions.
While past studies have looked at the social and economic impacts of microfinance-based SHGs, limited evidence is available on the potential of utilizing the existing and growing national and state government structures of microfinance-based SHGs. This article attempts to reduce deficiencies in the existing literature by analyzing the changes in ANC outcomes among women in Bihar who belong to an established microfinance-based program in which health, nutrition, and sanitation interventions are incorporated. The study employed a rigorous existing methodology and control group to compare the behaviors of women exposed to the health intervention with those not exposed to the health BCC intervention. Such a comparison will shed light on whether combining a health program with a microfinance-based SHG program, and taking it to scale, improves ANC practices and outcomes among the most marginalized populations, who are more often SHG members.

\section{Methods \\ Study design and setting}

This post-intervention study was conducted from June through August 2016, in eight intervention districts in Bihar, namely Patna, Saharsa, East Champaran, West Champaran, Samastipur, Begusarai, Gopalganj, and Khagaria. Located in the eastern part of India, Bihar is the country's third most populous state, with a population of 104 million, approximately $9 \%$ of the nation's population. Nearly $89 \%$ of Bihar is rural, and $17 \%$ of household heads in Bihar belong to a scheduled caste or tribe (SC/ ST) [13]. Nationally, Bihar has the highest population proportion in the lowest wealth quintile. Both neonatal and infant mortality rates in Bihar are higher than the national average [6].

Since 2006, the Government of Bihar has established SHGs for women, which are primarily microfinancebased institutions, popularly known as 'JEEViKA' [14]. Each SHG generally comprises 10 to 15 members, women who often belong to marginalized populations, i.e. SC/ST and poorest families. In 2015, JEEViKA worked with an implementing partner to introduce sessions on healthy maternal and child health practices within existing SHGs. The sessions on maternal and child health were conducted by health workers known as community mobilizers (CMs), who convene the SHG meetings. After training, CMs were expected to share messages on healthy maternal and child health practices once a month, in one of four weekly SHG meetings, over the course of a year, through participatory discussions, stories, and games. Eight discrete sessions were designed, with ANC discussed in four. In the sessions where ANC was discussed, women were advised to have four ANC checkups during pregnancy, to eat a balanced diet, 
receive necessary immunizations, and take IFA supplements. The aim of sharing this information was not only for pregnant women to learn about ANC behaviors, but to garner support from their fellow members to help their practice of those behaviors.

The groups of women in SHGs who were exposed to the health intervention were considered study cases, and those who were not part of the intervention (i.e. not provided with health $\mathrm{BCC}$ messaging) were considered the control group. The survey's inclusion criteria called for women who were SHG members and who had given birth to a live infant during the year preceding the survey.

\section{Sample size and sampling method}

A three-stage cluster sampling design selected the desired sample of SHG members. In the first stage, study blocks were randomly selected from two groups-blocks where the health BCC intervention was ongoing and blocks where the intervention was not present. In the second stage, villages were randomly selected from the selected blocks. In the third stage, SHGs were systematically selected from each of the selected villages. JEEViKA's list of SHGs was used as a sampling frame for SHG selection. If a SHG had no members who had given birth in the year preceding the survey, the field team replaced the group with another SHG in the village. All eligible women from every selected SHG were interviewed, using a structured interview schedule. The sample for this research came from a larger pre-post quasi-experimental study that evaluated the effect of BCC interventions on newborn care practices among the most marginalized women in SHGs [15].

A total sample of 1204 SHG women was estimated to detect the differences between the case and control arms for three key outcomes of interest-at least four ANC visits, safe delivery, awareness of sanitation-with $95 \%$ confidence and 5\% margin of error. This sample allowed inquiries about exposure to the intervention and ANC practices with minimum recall bias. Of the 1204 SHG women surveyed, 597 were from SHGs exposed to the health $\mathrm{BCC}$ intervention, residing in intervention blocks $(\mathrm{SHG}+\mathrm{H})$, and 607 belonged to SHGs not exposed to the health intervention, residing in non-intervention blocks (SHG only). The study design prevented contamination of the study arms.

\section{Data collection}

All research investigators were female, with bachelor's or master's degrees in either psychology or social work. Investigators were trained to be sensitive to potential confidentiality issues. Research investigators attended SHG meetings and identified eligible married women. Research staff then spoke to eligible women about the survey. If a woman indicated interest in participating, a private location, often at the potential respondent's home, or nearby, was identified for the consent process and subsequent interview. Face-to-face interviews were conducted by the trained, native investigators using a pre-coded questionnaire translated into the local language (Hindi). Women were asked about their knowledge, practice, and prevalent social norms regarding maternal and child health behaviors.

\section{Data management}

Survey data were collected using mini-laptops, employing a user-written computer program in CSPro (v6.0) with built-in validation checks. The program was designed to account for all skip patterns and ensure required questions were answered before proceeding. The data collected were reviewed by field supervisors to ensure accuracy and completeness. Data were checked weekly by a co-investigator in Delhi, India.

\section{Measures \\ Socio-demographic characteristics}

The socio-demographic characteristics considered in this paper are based on a single response question capturing a respondent's age, parity, caste, formal education, engagement in some occupation, and duration of SHG association. Formal education was defined as the ability to both read and write.

\section{Exposure to the intervention}

Exposure to the intervention was defined as women belonging to SHGs where health messages related to correct maternal and child health outcomes were delivered in at least one weekly group meeting per month.

\section{Outcome variables}

For this paper, healthy ANC practices were assessed by selecting nine outcome indicators that substantiate the benefits of combining maternal health programs and SHGs, namely: at least four ANC visits, IFA tablet or syrup regimen for at least 100 days, two TT injections, complete ANC (at least four ANC visits, two TT injections, IFA supplements for 100 or more days), ANC accompaniment by SHG members, information from community members (SHG members, CMs) on signs of pregnancy and delivery complications, treatment for pregnancy complications, ${ }^{1}$ supplementary food from Anganwadi center, and planning for place of delivery during pregnancy.

\footnotetext{
${ }^{1}$ Severe pregnancy related complication include weak or no movement of fetus, hypertension/ high BP, jaundice, excessive bleeding and convulsions
} 


\section{Statistical analyses}

Bivariate analyses explored select socio-demographic characteristics of women who belonged to the exposure group and those who belonged to the unexposed group. Chi-square tests checked the association of sociodemographic characteristics and exposure to health intervention. Differences between means were assessed using the student $\mathrm{T}$-test. All tests were double-sided and a $p$-value of less than 0.05 was considered statistically significant.

The radius caliper method of propensity score matching (PSM) was used to examine the impact of health intervention on ANC outcomes [16-18]. Each woman exposed to the health intervention was matched with an unexposed woman whose propensity score fell in a predefined neighborhood of the estimated propensity score of the exposed. All socio-demographic variables, namely age, parity, caste, formal schooling, employment, and duration of SHG membership, were used to calculate the propensity score. The propensity score was calculated using logistic regression, which had a dichotomous independent variable of interest, i.e. exposure to the intervention (where 1 = woman who belonged to SHG + $\mathrm{H}$ group and $0=$ woman who belonged to SHG only group) and observed socio-demographic characteristics as predictor variables.

The key assumption in the PSM approach was based on the propensity score where assignments to exposed and unexposed groups were considered random [19]. One test of this assumption was to examine the balancing property, which states that after matching the distribution of confounding factors is similar among exposed and matched unexposed groups [20]. To examine whether this balancing property was satisfied, differences in the socio-demographic characteristics of exposed women were compared to unexposed women, before and after matching, using the chi-square test (for percentages) and unpaired t-test (for mean values). The overall covariate imbalance of the model was examined by testing the joint significance of all the regressors (i.e. the ability of covariates to predict exposure to any intervention) using the likelihood ratio test before and after matching.

The difference in ANC outcomes between exposed and control groups was directly compared to show the impact of health $\mathrm{BCC}$ in the exposed group, known as the average treatment effect on treated (ATT). Additionally, comparing the difference in ANC outcomes between control and matched exposed groups showed the impact of exposure on the unexposed, known as the average treatment effect on the untreated (ATU) [21]. These two average effects were weighted by the proportion of SHG women in exposed and control groups, respectively, to arrive at the impact of the intervention exposure on outcomes, known as average treatment effect (ATE). Data were analyzed using STATA 11.0.

\section{Ethical considerations}

The evaluating institution's review board (IRB) reviewed and approved the study design and survey questionnaires. A comprehensive informed consent process was followed, with respondents informed about the study, including the interview's duration (approximately $45 \mathrm{~min}$ ), and any queries addressed before written consent was requested. In cases where respondents were illiterate or did not want to sign a consent form, verbal consent was taken. A copy of the written consent was provided to respondents, for their records. Participants were not given any monetary compensation for their time.

\section{Results}

Socio-demographic characteristics and exposure to health intervention

A description of the socio-demographic characteristics of the sample is presented in Table 1 . The mean age of respondents was about 27 years. Nearly $68 \%$ of SHG women had three or more children, and most (91.5\%) were SC/ST. Around one fourth (25.2\%) of surveyed SHG women had a formal education, and nearly twofifths (39.1\%) were engaged in some occupation. About $60 \%$ of women reported an association with an SHG for 25 or more months, $28 \%$ for 13 to 24 months, and nearly $12 \%$ for 1 year or less (Table 1 ).

SHG women exposed to the health intervention differed significantly from all unexposed SHG women in almost all socio-demographic characteristics (Table 1), but no significant differences were found when SHG women exposed to the health intervention were compared with matched unexposed SHG women (Table 2). For example, the percentage of women engaged in some occupation in the two groups was highly significant $(p-$ value $<0.001$ ) before matching, but after matching they were not significantly different (p-value 0.212 ). The likelihood ratio Chi-square statistic computed to test the joint significance of covariates reduced significantly after matching among SHG women (before matching: $\chi^{2}$ statistic $=210.7, p$-value $<0.001$; after matching: $\chi^{2}$ statistic $=$ 2.01, p-value 0.959).

\section{Impact of health intervention on ANC outcomes}

The impact of health intervention exposure on ANC behaviors in matched samples of exposed and unexposed SHG women is presented in Table 3.

Results suggest that exposure to the health intervention increased the likelihood of: 1) at least four ANC visits among SHG women (ATE $=7.2$, 95\% CI: $0.76-$ 13.7, $p$-value $<0.05), 2$ ) consumption of IFA for at least 100 days $(\mathrm{ATE}=8.7,95 \% \mathrm{CI}: 5.0-12.5$, p-value $<0.001$ ), 
Table 1 Socio-demographic characteristics and exposure to health intervention among women who are part of self-help groups, Bihar, India, 2016 ( $N=1204)$

\begin{tabular}{|c|c|c|c|c|}
\hline \multirow[t]{3}{*}{ Socio-demographic characteristics } & \multicolumn{4}{|c|}{ Women who belong to self-help groups } \\
\hline & Overall percentage and mean & Exposed to health intervention & Unexposed & $p$-value ${ }^{c}$ \\
\hline & $(N=1204)$ & $(N=597)$ & $(N=607)$ & \\
\hline Mean age in years (SD) & $26.8(4.9)$ & $27.5(5.0)$ & $26.1(4.7)$ & $<0.001^{* * *}$ \\
\hline Had 3 or more children & 68.2 & 77.4 & 59.1 & $<0.001^{* * *}$ \\
\hline Belongs to $\mathrm{SC} / \mathrm{ST}^{\mathrm{a}}$ & 91.5 & 91.6 & 91.4 & 0.905 \\
\hline Formal schooling ${ }^{b}$ & 25.2 & 17.9 & 32.3 & $<0.001^{* * *}$ \\
\hline SHG women engaged in some occupation & 39.1 & 43.7 & 34.6 & $<0.001^{* * *}$ \\
\hline \multicolumn{5}{|l|}{ Duration of association with SHG } \\
\hline Less than equal to 12 months & 11.7 & 3.5 & 19.8 & $<0.001^{* * *}$ \\
\hline 13-24 months & 28.2 & 19.3 & 37.1 & $<0.001^{* * *}$ \\
\hline 25 or more months & 60.1 & 77.2 & 43.1 & $<0.001^{* * *}$ \\
\hline
\end{tabular}

SD standard deviation

${ }^{*} p<0.10 ;{ }^{* *} p<0.05 ;{ }^{* * *} p<0.01$

a SC Scheduled Caste, ST Scheduled Tribe

${ }^{b}$ Formal schooling refers to the ability to both read and write

${ }^{c} p$ values were obtained by comparing percentages for those who were exposed to health intervention and those who were not exposed to health intervention. Differences in percentages were tested using $X^{2}$ test statistics and differences in average values were tested using unpaired $t$ statistic

and 3) complete ANC (ATE =3.6, 95\% CI: 2.3-4.9, pvalue $<0.001)$, when compared to women not exposed to the health intervention. Exposure to health intervention also showed an increase in other related ANC outcomes such as ANC accompaniment by SHG members, information on signs of pregnancy and delivery complications, and delivery planning (Table 3). Exposure to health intervention was not found to have impacts on two TT injections or seeking treatment for pregnancyrelated complications among SHG members.

Table 2 Matching socio-demographic characteristics of SHG women who were not exposed to health intervention with those who were exposed, Bihar, India, 2016

\begin{tabular}{llll}
\hline Women who belong to self-help groups & & & \\
\hline Socio-demographic characteristics & Exposed to health intervention & Matched unexposed & $p$-value \\
\hline Mean age in years (SD) & $27.5(4.6)$ & $27.4(4.4)$ & 0.917 \\
Had 3 or more children & 77.4 & 77.9 & 0.831 \\
Belongs to SC/ST a & 91.6 & 90.6 & 0.540 \\
Formal schooling b & 17.9 & 18.6 & 0.771 \\
SHG women engaged in some occupation & 43.7 & 40.1 & 0.212 \\
Duration of association with SHG & & 3.7 & 0.896 \\
Less than equal to 12 months & 3.5 & 19.3 & 0.992 \\
13-24 months & 19.3 & 77.0 & 0.947 \\
25 or more months & 77.2 & 598 &
\end{tabular}

Likelihood ratio $\times 2$ test statistic ( $p$ value) ${ }^{\text {e }}$

\begin{tabular}{ll} 
Before matching & $210.69(<0.001)$ \\
After matching & $2.01(0.959)$ \\
\hline
\end{tabular}

SD standard deviation

${ }^{*} p<0.10 ;{ }^{* *} p<0.05 ;{ }^{* * *} p<0.01$

a SC-Scheduled Caste, ST-Scheduled Tribe

${ }^{b}$ Formal schooling refers to the ability to both read and write

c Differences in $\mathrm{N}$ values for matched unexposed and unexposed is the number of unexposed cases dropped from the analysis as no match could be found for them

${ }^{d} p$ values were obtained by comparing percentages for those who were exposed to health intervention and matched unexposed SHG women. Matched unexposed refers to SHG women who were unexposed to health intervention and had propensity scores similar to that for those exposed SHG women. Differences in percentages were tested using $x^{2}$ test statistics and differences in average values were tested using unpaired $t$ statistic

e The likelihood ratio $x^{2}$ test statistic was used to test the joint significance of all the regressors before and after matching 
Table 3 Estimated impact of exposure to health interventions on antenatal care-related outcomes among self-help group women, Bihar, India, 2016

\begin{tabular}{|c|c|c|c|c|c|c|c|c|}
\hline \multirow[t]{2}{*}{ Health behavior outcomes } & \multicolumn{2}{|c|}{ After matching } & \multicolumn{3}{|c|}{$\begin{array}{l}\text { Average effect of } \\
\text { exposure among } \\
\text { exposed }\left(A T^{\mathrm{e}}\right)\end{array}$} & \multicolumn{3}{|c|}{$\begin{array}{l}\text { Expected increase in } \\
\text { health behavior (ATE }{ }^{f} \text { ) }\end{array}$} \\
\hline & Exposed \% & Unexposed \% & $\mathrm{ATT}$ & 95\% Cl for ATT & p-value & ATE & 95\% Cl for ATE & $p$-value \\
\hline Had 4 or more antenatal care visits & 15.8 & 10.8 & 5.0 & $(-0.8,10.8)$ & 0.09 & 7.2 & $(0.76,13.7)^{* *}$ & 0.03 \\
\hline $\begin{array}{l}\text { Took iron folic acid tablets/syrup for } \\
\text { at least } 100 \text { days }\end{array}$ & 14.9 & 7.5 & 7.4 & $(0.1,14.5) * *$ & 0.04 & 8.7 & $(5.0,12.5) * * *$ & $<0.001$ \\
\hline Received 2 TT injections & 77.3 & 83.9 & -6.6 & $(-10.2,-2.9) * * *$ & $<0.001$ & -4.8 & $(-10.1,0.5)$ & 0.07 \\
\hline Received full ANC ${ }^{a}$ & 4.2 & 1.6 & 2.6 & $(0.3,4.9) * *$ & 0.03 & 3.6 & $(2.3,4.9) * * *$ & $<0.001$ \\
\hline Accompanied by SHG members for ANC visits & 27.9 & 13.6 & 14.2 & $(10.9,17.5) * * *$ & $<0.001$ & 13.0 & $(7.2,18.9)^{* * *}$ & $<0.001$ \\
\hline $\begin{array}{l}\text { Received information on signs of pregnancy } \\
\text { and delivery complications from community members }\end{array}$ & 46.0 & 28.0 & 18.0 & $(12.6,23.3) * * *$ & $<0.001$ & 20.9 & $(11.5,30.3) * * *$ & $<0.001$ \\
\hline Sought treatment for pregnancy complications ${ }^{c}$ & 27.5 & 23.5 & 4.0 & $(-0.5,8.5)$ & 0.08 & 2.4 & $(-3.2,7.9)$ & 0.40 \\
\hline Received supplementary food from Anganwadi center & 54.2 & 51.9 & 2.3 & $(-0.2,4.8)$ & 0.26 & 2.7 & $(0.5,4.9) * *$ & 0.01 \\
\hline Planned for place of delivery during pregnancy ${ }^{d}$ & 94.5 & 88.3 & 6.2 & $(1.2,11.1) * *$ & 0.01 & 6.5 & $(2.4,10.6) * * *$ & $<0.001$ \\
\hline
\end{tabular}

${ }^{*} p<0.10 ;{ }^{* *} p<0.05 ;{ }^{* * *} p<0.01$

${ }^{a}$ Full ANC is defined as receiving 4 or more antenatal care visits, $2 \pi$ injections and consumption of 100 or more iron-folic acid tablets during pregnancy

${ }^{b}$ Information on signs of pregnancy and delivery complications such as swelling of hands, paleness, weakness, visual disturbances, excessive fatigue, weak or no movement of fetus, abnormal position of fetus, excessive vomiting, hypertension, jaundice, excessive bleeding, convulsions, prolonged labor, obstructed labor, foul-smelling discharge, delay in placental expulsion or retained placenta, cord prolapsed/ baby's hand and feet coming out first and cord around the neck of the baby from community members like SHG leader, SHG members, Saheli or Community Mobilizer

c Severe pregnancy-related complication such as weak or no movement of the fetus, hypertension/ high BP, jaundice, excessive bleeding and convulsions

${ }^{d}$ Prior to delivery planned to deliver the child at home or in a healthcare facility

e Average treatment effect for the treated (ATT)/ exposed SHG women measured the impact of the intervention on exposed SHG women

${ }^{f}$ Average treatment effect (ATE) represents the impact of the program obtained by averaging the impact across all the individuals (exposed and unexposed

\section{Discussion}

The findings from this study, following an intervention that provided information on correct ANC to women in SHGs, reveal significant increases in most ANC outcomes within 1 year of the intervention, compared to unexposed matched SHG women, after controlling for respondents' socio-demographic characteristics. This is consistent with similar research on the effects of SHG interventions, demonstrating that combining a health program with microfinance-based SHG activities is associated with significant increases in maternal care services $[12,22]$. As evident from other studies conducted in Nepal and Maharashtra, leveraging microfinance-based SHGs to promote health outcomes is beneficial to the health and well-being of their members [23]. This study adds to existing evidence by drawing attention to the significant improvement in ANC practices due to a scaled-up intervention focused among the most marginalized populations.

Improvements in several ANC practices can be explained by an increase in SHG members reporting accompaniment by fellow group members to ANC visits. This reveals that SHGs are not only a platform to alleviate poverty, but are an efficient and effective model for building social capital through collectivization and cohesion, which play a vital role in the development of marginalized populations [12, 23, 24]. Health information supplied through SHGs provides an added benefit of mutual support among members for ANC service access. Sharing health messages in SHG meetings changed the normative practice of ANC in these communities, benefiting highly marginalized women. As a result of this changing environment, frontline workers may also become more proactive in following up with pregnant women for ANC service and providing them with timely care throughout pregnancy.

This study did not find any difference in either group of women for the treatment of pregnancy complications. As recognized by studies in other low- and middleincome countries, pregnant women do not seek treatment due to factors ranging from lack of information, financial constraints, multiparity, in addition to cultural factors $[4,25]$. Focused interventions with male involvement have shown some results in improved healthseeking behavior of pregnant women, which was not the focus on this intervention [26-28]. Further research is needed in Bihar to identify how efforts can be made to increase treatment-seeking for pregnancy complications by empowering women to seek care, increasing their financial independence, for better health service access, and engaging family members, in case of a health emergency. No differences in both groups were found for TT injections either, which could be due in part to interrupted or irregular injection supplies.

For the ANC outcomes that did not show changes as expected, in the group that received health messaging, 
periodic reviews of meeting and messaging content, quality of message conveyance, and frequency of delivery in various locations may be helpful [29]. In addition to examining individual behaviors, any challenges CMs faced in delivering health messages should be addressed.

While these findings provide important insights on the effect of sharing health messages with SHG members, they must be interpreted in relation to certain study limitations. First, the outcome indicators for ANC were based on self-response, which is susceptible to both social desirability and recall bias. The potential for recall bias was reduced by recruiting trained and experienced enumerators for the interviews, and by selecting mothers who had a live birth in the 12 months preceding the survey. Secondly, the findings are specific to eight blocks from selected districts of Bihar and cannot be generalized to other states. Replication of this study in other settings requires further research. Lastly, PSM relies on the conditional independence assumption, that is, all available variables considered to be a predictor of exposure to health intervention are included in the model used to estimate propensity scores. It is possible that some potential predictors of exposure to the health intervention were not available from our study, such as wealth index or frequency of contact with frontline workers, and therefore could not be accounted for in the analysis.

\section{Conclusions}

These study findings reiterate that health messaging through existing microfinance-based SHGs is a viable approach for improved ANC practice. Exposure to health messages within SHGs is associated with an increased likelihood of at least four ANC visits among SHG women, IFA consumption for at least 100 days, and complete ANC when compared to SHG women not exposed to the health intervention. This approach helps reduce current deficiencies in information on correct ANC practices while increasing the demand for health services and encouraging pregnant women to seek ANC from healthcare providers.

With nearly seven million households involved in SHGs organized by JEEViKA, and more expected to join due to the support of important state authorities, SHGs have the potential to increase social capital and reach among the most marginalized populations at an unprecedented scale. This health BCC intervention could be scaled up throughout Bihar in a phased manner. Health messages can also be individuated to specific groups' or members' needs, through systematic training and capacity-building of CMs, who are responsible for delivering the health modules.

Periodic observations, monitoring, reviews, and recommendations would strengthen the program's internal quality and monitoring. Further research is needed to measure the sustainability of this integrated approach and identify optimal program frequency, for continuous improvements in health outcomes. Exploring the diffusion of health messages through wider communities, beyond those families with direct SHG involvement, and its impact on targeted practices apart from SHG members and their families would be worthwhile as well.

\section{Abbreviations}

ANC: Antenatal care; ATE: Average treatment effect; ATT: Average treatment effect on treated; ATU: Average treatment effect on untreated;

CM: Community mobilizer; IFA: Iron folic acid; MMR: Maternal mortality ratio; PSM: Propensity score matching; SC/ST: Scheduled castes/ scheduled tribes; SHG: Self-help group; T: Tetanus toxoid; WHO: World Health Organization

\section{Acknowledgments}

The authors acknowledge the support from the implementing organization, the government entity supporting self-help groups, and the men and women who participated in this study.

\section{Authors' contributions}

MW and LI drafted the paper. MW conducted the analysis. IC, YA, and NS have reviewed and provided inputs to the manuscript. All authors read the approved the final manuscript.

\section{Funding}

This evaluation study was funded by the [name retracted to ensure anonymity] (\#OPP1141832) and [name retracted to ensure anonymity] (061CXX1ZZ-140700). The evaluation agency has designed and conducted the study on their own. The funders had no role in study design, data collection, data analysis or interpretation and decision to publish.

\section{Availability of data and materials}

The dataset used and/or analyzed during the current study are available from the following link: [link retracted to ensure anonymity].

\section{Ethics approval and consent to participate}

The study was reviewed and approved by the institution's ethical review board. Ethical approval for the study was sought from the institutional IRB. A comprehensive informed consent process was followed, with respondents informed about the study, including the interview's duration (approximately $45 \mathrm{~min}$ ), and their queries addressed before written consent was taken. In cases where respondents were illiterate or did not want to sign a consent form, verbal consent was taken. A copy of the written consent was provided to respondents for their records. Participants were not given any monetary compensation for their time.

\section{Consent for publication}

Written consent was taken from all participants to participate in the study and share the findings from this study. A hard copy of the consent form was left with the participant for their records.

\section{Competing interests}

The authors declare that they have no competing interests.

\section{Author details}

'Population Council, Zone 5A, Ground Floor India Habitat Centre, Lodi Road, New Delhi, Delhi 110003, India. ${ }^{2}$ Project Concern International, 38, Okhla Phase 3 Rd, Okhla Phase III, Okhla Industrial Area, New Delhi, Delhi 110020, India. ${ }^{3}$ Bill \& Melinda Gates Foundation, Capital Court, 5th Floor, Olof Palme Marg, Munirka, Delhi, India.

Received: 25 May 2019 Accepted: 3 February 2020

Published online: 07 February 2020

References

1. Ministry of Statistics and Programme Implementation I. Millennium Development Goals: India Country Report 2015. Social Statistics Division, 
Central Statistics Offfice, Ministry of Statistics and Programme Implementation; 2015

2. Bergsjo P. What is the evidence for the role of antenatal care strategies in the reduction of maternal mortality and morbidity? 2001.

3. Bloom SS, Lippeveld T, Wypij D. Does antenatal care make a difference to safe delivery? A study in urban Uttar Pradesh, India. Health Policy Plan. 1999; 14(1):38-48.

4. Finlayson $\mathrm{K}$, Downe $\mathrm{S}$. Why do women not use antenatal services in lowand middle-income countries? A meta-synthesis of qualitative studies. PLoS Med. 2013;10(1):e1001373.

5. International Institute of Population Sciences. National Family Health Survey (NFHS-4), 2015-16. Mumbai: International Institute for Population Sciences; 2016.

6. International Institute of Population Sciences. Bihar state fact sheet: National Family Health Survey-4, 2015-16. Mumbai: Ministry of Health and Family Welfare; 2017.

7. Mumbare SS, Rege R. Ante natal care services utilization, delivery practices and factors affecting them in tribal area of North Maharashtra. Indian J Community Med. 2011:36(4):287-90

8. Lassi ZS, Haider BA, Bhutta ZA. Community-based intervention packages for reducing maternal and neonatal morbidity and mortality and improving neonatal outcomes. Cochrane Database Syst Rev. 2010;11: CD007754.

9. Saha S, Kermode M, Annear PL. Effect of combining a health program with a microfinance-based self-help group on health behaviors and outcomes. Public Health. 2015;129(11):1510-8.

10. Singh R, Neogi SB, Hazra A, Irani L, Ruducha J, Ahmad D, et al. Utilization of maternal health services and its determinants: a cross-sectional study among women in rural Uttar Pradesh, India. Journal of Health, Population and Nutrition. 2019;38(1):13.

11. Manandhar DS, Osrin D, Shrestha BP, Mesko N, Morrison J, Tumbahangphe KM, et al. Effect of a participatory intervention with women's groups on birth outcomes in Nepal: cluster-randomised controlled trial. Lancet. 2004; 364(9438):970-9.

12. Saha $S$, Annear P, Pathak $S$. The effect of self-help groups on access to maternal health services: evidence from rural India. Int J Equity Health. 2013; 12(1):36.

13. Government of India. SRS Statistical Report 2011: Office of the Registrar General \& Census Commissioner, India, Ministry of Home Affairs, Government of India; 2011 [Available from: http://www.censusindia.gov.in/ vital_statistics/SRS_Reports.html.

14. Bihar Rural Livelihoods Promotion Society. JEEViKA, An inititative of Government of Bihar for Poverty Alleviation Patna, Bihar: Bihar Rural Livelihoods Promotion Society; 2009-2010 [Available from: http://brlp.in.

15. Saggurti N, Porwal A, Atmavilas Y, Walia M, Das R, Irani L. Effect of behavioral change intervention around new-born care practices among most marginalized women in self-help groups in rural India: analyses of three cross-sectional surveys between 2013 and 2016. J Perinatol. 2019; 39(7):990-9.

16. Rosenbaum P, Rubin D. Constructing a control group using multivariate matched sampling methods that incorporate the propensity score. Am Stat. 1985;39(1):33-8

17. Stuart EA. Matching methods for causal inference: a review and a look forward. Stat Sci. 2010;25(1):1-21.

18. D'Agostino RB Jr. Propensity score methods for bias reduction in the comparison of a treatment to a non-randomized control group. Stat Med. 1998;17(19):2265-81.

19. Rosenbaum $P$, Rubin $D$. The central role of the propensity score in observational studies for causal effects. Biometrika. 1983;70(1):41-55.

20. Austin $\mathrm{PC}$, Grootendorst $\mathrm{P}$, Anderson GM. A comparison of the ability of different propensity score models to balance measured variables between treated and untreated subjects: a Monte Carlo study. Stat Med. 2007;26(4): 734-53.

21. Yadav D, Ramanathan S, Goswami P, Ramakrishnan L, Saggurti N, Sen S, et al. Role of community group exposure in reducing sexually transmitted infection-related risk among female sex workers in India. PLoS One. 2013; 8(10):e78361.

22. Tripathy P, Nair N, Barnett S, Mahapatra R, Borghi J, Rath S, et al. Effect of a participatory intervention with women's groups on birth outcomes and maternal depression in Jharkhand and Orissa, India: a cluster-randomised controlled trial. Lancet. 2010;375(9721):1182-92.
23. Saha S. Expanding health coverage in India: role of microfinance-based selfhelp groups. Glob Health Action. 2017:10(1):1321272.

24. Kanak S, liguni Y. Microfinance programs and social capital formation: the present scenario in a rural village of Bangladesh. The International journal of applied economics and finance. 2007;1 (2):97-104.

25. McDonagh $\mathrm{M}$. Is antenatal care effective in reducing maternal morbidity and mortality? Health Policy Plan. 1996;11(1):1-15.

26. Catholic Relief Services (CRS). An innovative approach to involving men in maternal and newborn health care: Program experiences in the Department of Matagalpa, Nicaragua. Baltimore: Catholic Relief Services; 2014.

27. Ditekemena J, Koole O, Engmann C, Matendo R, Tshefu A, Ryder R, et al. Determinants of male involvement in maternal and child health services in sub-Saharan Africa: a review. Reprod Health. 2012;9:32.

28. Yargawa J, Leonardi-Bee J. Male involvement and maternal health outcomes: systematic review and meta-analysis. J Epidemiol Community Health. 2015;69(6):604-12.

29. Charlet D, Moran AC, Madhavan S. Summary findings from a mixed methods study on identifying and responding to maternal and newborn illness in seven countries: implications for programs. J Health Popul Nutr. 2017;36(Suppl 1):48.

\section{Ready to submit your research? Choose BMC and benefit from:}

- fast, convenient online submission

- thorough peer review by experienced researchers in your field

- rapid publication on acceptance

- support for research data, including large and complex data types

- gold Open Access which fosters wider collaboration and increased citations

- maximum visibility for your research: over $100 \mathrm{M}$ website views per year

At BMC, research is always in progress.

Learn more biomedcentral.com/submissions 